\title{
Analysis of trace elements in human hair through X-ray fluorescence spectroscopy for screening of prostate cancer
}

\author{
Majid Ghanbari Birgani ${ }^{1}$, Reza Reiazi*1,2 (D), Mahdieh Afkhami Ardekani ${ }^{3}$, Hamed Ghaffari ${ }^{1}$, Ali Shakeri-Zadeh ${ }^{1}$, \\ Bahram Mofid ${ }^{4}$
}

Received: 7 Dec 2019

Published: 28 Jul 2020

\section{Abstract}

Background: Use of hair samples to analyze the trace element concentrations is one of the interesting fields among many researchers. X-ray fluorescence (XRF) is considered as one of the most common methods in studying the concentration of elements in tissues and also crystalline materials, using low energy X-ray. In the present study, we aimed to evaluate the concentration of the trace elements in the scalp hair sample through XRF spectroscopy using signal processing techniques as a screening tool for prostate cancer.

Methods: Hair samples of 22 men (including 11 healthy and 11 patients) were analyzed. All the sample donors were Iranian men. EDXRF method was used for the measurements. Signals were analyzed, and signal features such as mean, root-mean-square (RMS), variance, and standard deviation, skewness, and energy were investigated. The Man-Whitney U test was used to compare the trace element concentrations. The analysis of variance (ANOVA) test was used to identify which extracted feature could help to identify healthy and patient people. P values $\leq 0.05$ were considered statistically significant. Statistical analysis was performed using SPSS 16.0 software.

Results: The mean \pm SD age was $67.8 \pm 8.7$ years in the patient group and $61.4 \pm 6.9$ years in the healthy group. There were statistically significant differences in the aluminum ( $\mathrm{A} 1, \mathrm{P}<0.001)$, silicon $(\mathrm{Si}, \mathrm{P}=0.006)$, and phosphorus $(\mathrm{P}, \mathrm{P}=0.028)$ levels between healthy and patient groups. Skewness and variance were found to be relevant in identifying people with cancer, as signal features.

Conclusion: The use of EDXRF is a feasible method to study the concentration of elements in the hair sample, and this technique may be effective in prostate cancer screening. Further study with a large sample size will be required to elucidate the efficacy of the present method in prostate cancer screening.

Keywords: Prostate cancer, Hair sample, XRF, Prostate screening, Signal processing

Conflicts of Interest: None declared

Funding: This study has received funding by Iran University of Medical Sciences, Tehran, Iran (grant number: 30639).

\section{*This work has been published under CC BY-NC-SA 1.0 license. \\ Copyright $\odot$ Iran University of Medical Sciences}

Cite this article as: Ghanbari Birgani M, Reiazi R, Afkhami Ardekani M, Ghaffari H, Shakeri-Zadeh A, Mofid B. Analysis of trace elements in human hair through X-ray fluorescence spectroscopy for screening of prostate cancer. Med J Islam Repub Iran. 2020 (28 Jul);34:86. https://doi.org/10.47176/mjiri.34.86

\section{Introduction}

Cancer is known as a major global public health issue $(1,2)$. Among different types of cancers, prostate cancer is considered as one of the most common malignancies in men worldwide. Although the main cause of prostate cancer is unknown, several risk factors, including zinc deficiency and calcium, are well known. It has also been

Corresponding author: Dr Reza Reiazi, reiazi.r@iums.ac.ir

1. Department of Medical Physics, School of Medicine, Iran University of Medical Sciences, Tehran, Iran

2. Medical Image and Signal Processing Research Core, Iran University of Medical Sciences, Tehran, Iran

3. Department of Radiology, Faculty of Para-Medicine, Hormozgan University of Medical Sciences, Bandar-Abbas, Iran

4. Department of Radiation Oncology, Shohada-e-Tajrish Medical Center, Shahid Beheshti University of Medical Sciences, Tehran, Iran proven that the risk of developing prostate cancer increases with age; for example, for ages 70 to 79 , the risk of prostate cancer is 3 times more than the age of $39(1,3-7)$.

The level of serum prostate-specific antigen (PSA) alone cannot detect prostate cancer at an early stage, and in many cases, the level of PSA increases with another

$\uparrow$ What is "already known" in this topic:

Several studies have investigated X-ray fluorescence (XRF) technique to find a relationship between elements' concentration and cancers such as breast, colon, and prostate.

$\rightarrow$ What this article adds:

Herein, we analyzed trace elements in human scalp hair using XRF spectroscopy through signal processing techniques. Skewness and variance were found to be relevant in identifying healthy and cancerous groups, as signal features. 
disease, such as prostate hyperplasia and non-neoplastic conditions, which reduces the ability to detect cancer. Trace elements have important physiological functions, such as maintaining and regulating cell function, regulating the gene, activating or preventing enzymatic reactions, and regulating cell membrane function. The essential or toxic properties (mutagen and cariogenic) of the trace elements depend on tissue and tissue tolerance, respectively. Excessive accumulation or an imbalance condition of the trace elements may disrupt cell function and can lead to cell degeneration, death, or malignant transmission (6-12).

In screening of prostate cancer, invasive techniques such as prostate biopsy or less invasive approaches such as digital rectal examination (DRE) are used in conjunction with the PSA test. Studies have shown that analyzing the level of trace elements using X-ray fluorescence (XRF) spectroscopy in the hair sample of people with breast cancer is much lower than that of healthy people. It also has a much higher sensitivity to mammography. Generally, this test may be a low-cost and non-invasive screening tool. This technique has the ability to perform elemental analysis in qualitative and semi-quantitative samples, especially mineral samples. As a result of X-ray irradiation and sample excitation, an electron transfer occurs in different layers of the atom, where each electron transfer is associated with the emission of a spectral X-ray spectrum, followed by the detection of the specific radiation produced by the detector. The wavelength of the distributed spectral lines is based on the quality degradation of the elements and the intensity of the beams according to the frequency or quantity of the elements in the sample (12-23).

The purpose of this study was to investigate the concentration of the trace elements in the scalp hair sample through XRF spectroscopy using signal processing techniques as a screening tool for prostate cancer.

\section{Methods}

\section{Patient selection}

In the current study, the participants are divided into healthy and patient groups, with 11 people in each group. All people were originally Iranian and had an Iranian diet. All participants in this study signed a written informed consent. The patient group included people with histologically confirmed prostate cancer.

\section{Preparation of hair samples}

Initially, we explained the procedure to all participants to resolve the existing ambiguities, and then healthy and patient hair samples were provided. The hairs of all people were prepared from the back area. Inclusion criteria were the lack of a history of chemotherapy in the last 6 months, lack of hair loss for at least 2 months, and lack of hair color history for at least 2 months before sampling. The approximate length of the hairs cut from the head was about the size of a circle with a diameter of one centimeter. All hairs were scissored from the hair shaft and then placed in special bags with each patient's specific code. Before placing the specimen against X-rays, it is necessary to convert the hair sample to the powder. There are several methods for the preparation of hair powder, which uses a physical solution for the preparation of hair powder in this study. All hairs were washed to prevent any contamination before the analysis. Each hair sample was placed in a separate beaker and washed in the following four steps: 1) immerse the hair in $50 \mathrm{ml}$ of acetone for 15 minutes; 2) removing acetone from the beaker and immerse hair in $50 \mathrm{~mL}$ of distilled water for 15 minutes, 3) after step 2, repeat step 1 again; 4) after step 3, we repeat step 2 again. After washing the hair samples, hair follicles were placed in an oven at $80^{\circ} \mathrm{C}$ for 4 hours. The purpose of this step was to have all the specimens completely dried and prepared for the next steps.

Then, the hairs were tweaked with scissors and placed in a mortar. The liquid was then poured into the masonry and then poured into the powder using a bundle of moles. The purpose of this technique is to increase the fragility of the hairs caused by nitrogen. After pouring samples, each specimen was placed in a special container that was washed with nitric acid and distilled water, and the patient code was written on the dish. All specimens should be converted to solids for analysis using boric acid. To prepare the pill, 5 grams of boric acid was first poured into the hydraulic press compartment, and then the hair powder was placed on that surface, and the pressure was applied for two minutes at 10 tons per square centimeter. Then the pills were placed in separate plastics where the patient codes were written.

\section{Sample analysis}

The experiments conducted in the field of XRF using the SPECTRO XEPOS energy dispersive XRF (ED-XRF) spectrometer (Germany). For spectroscopy of samples, all specimens were initially placed in a special holder and then the following setting was considered for them: 1) the radiation range of $\mathrm{X}$-ray radiation emitted to the samples was 20 to 40 electron volts; 2) the X-ray intensity range of the samples was 30 to $40 \mathrm{~mA}$ per second; 3) the duration of each test was about 40 minutes. After hair and specimens were prepared, they were placed in a sample holder and exposed to fluorescence spectroscopy. Output pulses from the detector were transmitted to a multi-channel analyzer connected to a computer for processing. A multichannel analyzer converts each analog pulse into digital data for processing, then stores it in memory, and eventually displays the processed information in the form of counting against the channel number. In this study, spectral patterns from fluorescence spectroscopy were compared between healthy and patient hair samples, and the dependence of spectral changes on the amount of these elements in healthy and patient hair samples was determined.

\section{Signal analysis}

Signal processing was performed using MATLAB R2014a software. Before the main processing, the spectra obtained underwent preprocessing methods such as noise reduction methods, and appropriate sections of the spectrum were analyzed. Signal distribution methods in this study include, mean, root-mean-square (RMS), variance, 
standard deviation, skewness, energy, and autocorrelation. The median, as the first method for evaluating the signal, was calculated as follows:

$$
x_{\text {ave }}=\frac{1}{N} \sum_{K=1}^{N} X_{K}
$$

The RMS was calculated using the following equation:

$$
x_{R M S}=\left[\frac{1}{N} \sum_{k=1}^{N} X_{k}^{2}\right]^{1 / 2}
$$

The variance measures the number of signal changes, regardless of the mean, as defined below

$$
\sigma^{2}=\frac{1}{N-1} \sum_{k=1}^{N}\left(X_{k}-X_{\text {ave }}\right)^{2}
$$

The standard deviation of the signal changes was calculated as follows.

$$
\square=\left[\frac{1}{N-1} \sum_{k=1}^{N}\left(X_{k}-X_{\text {ave }}\right)^{2}\right]^{1 / 2}
$$

The skewness was calculated using the following formula:

$$
S K=\frac{\frac{1}{N} \sum_{k=1}^{N}\left(X_{k}-X_{\text {ave }}\right)^{3}}{\sigma^{3}}
$$

The energy signal was calculated using the following equation:

$$
E_{x}=\int_{-\infty}^{+\infty}|x(t)|^{2} d t
$$

The autocorrelation was calculated using the following equation:

$$
\text { Autocorrelation }=r_{x x(\tau)}=\frac{1}{T} \int_{0}^{T} x(t) x(t+\tau) d t
$$

\section{Statistical analysis}

Statistical analysis was performed using SPSS 16.0 software. The normal distribution of data was investigated using the Shapiro-Wilk test. The Mann-Whitney U test was used for comparison of the trace element concentrations in the cancerous and healthy groups. The analysis of variance (ANOVA) test was used to identify which extracted feature could help to identify healthy and patient people. $\mathrm{P}$ values $\leq 0.05$ were considered statistically significant.

\section{Results}

The mean \pm standard deviation (SD) age was $67.8 \pm 8.7$ years in the patient group and $61.4 \pm 6.9$ years in the healthy group. The mean $\pm \mathrm{SD}$ of PSA of patient and healthy samples was $11.3 \pm 5.5 \mathrm{ng} / \mathrm{ml}$ and $0.6 \pm 0.04 \mathrm{ng} / \mathrm{ml}$, respectively.

Table 1 shows the mean \pm SD trace element concentrations in healthy and patient groups. The results of the Mann-Whitney $\mathrm{U}$ showed that there is a significant difference in aluminum ( $\mathrm{Al}, \mathrm{P}<0.001$ ), silicon $(\mathrm{Si}, \mathrm{P}=0.006$ ), and phosphorus $(\mathrm{P}, \mathrm{P}=0.028)$ concentration between healthy and patient groups, as outlined in Table 1.

The results of the mathematical conversion of the discrete

\begin{tabular}{|c|c|c|c|c|}
\hline Material code & Trace element & & Mean \pm SD concentration $(\%)$ & $\mathrm{p}$ \\
\hline \multirow[t]{2}{*}{1} & Sodium $(\mathrm{Na})$ & Healthy & $9.60 \pm 0.53$ & 0.341 \\
\hline & & Patient & $8.8 \pm 2.13$ & \\
\hline \multirow[t]{2}{*}{2} & Magnesium (Mg) & Healthy & $0.86 \pm 0.04$ & 0.358 \\
\hline & & Patient & $0.8 \pm 0.2$ & \\
\hline \multirow[t]{2}{*}{3} & Aluminum (Al) & Healthy & $0.00 \pm 0.00$ & $<0.001$ \\
\hline & & Patient & $0.002 \pm 0.0$ & \\
\hline \multirow[t]{2}{*}{4} & Silicon (Si) & Healthy & $0.13 \pm 0.17$ & 0.006 \\
\hline & & Patient & $0.0 \pm 0.0$ & \\
\hline \multirow[t]{2}{*}{5} & Phosphorus (P) & Healthy & $0.73 \pm 0.03$ & 0.028 \\
\hline & & Patient & $0.65 \pm 0.16$ & \\
\hline \multirow[t]{2}{*}{6} & Sulfur (S) & Healthy & $18.0 \pm 1.18$ & 0.870 \\
\hline & & Patient & $17.0 \pm 4.0$ & \\
\hline \multirow[t]{2}{*}{7} & Chlorine $(\mathrm{Cl})$ & Healthy & $0.74 \pm 0.86$ & 0.974 \\
\hline & & Patient & $0.9 \pm 1.2$ & \\
\hline \multirow[t]{2}{*}{8} & Potassium $(\mathrm{K})$ & Healthy & $0.45 \pm 0.80$ & 0.768 \\
\hline & & Patient & $0.43 \pm 0.61$ & \\
\hline \multirow[t]{2}{*}{9} & Calcium $(\mathrm{Ca})$ & Healthy & $1.40 \pm 0.65$ & 0.158 \\
\hline & & Patient & $1.05 \pm 0.8$ & \\
\hline \multirow[t]{2}{*}{10} & Titanium (Ti) & Healthy & $0.01 \pm 0.01$ & 0.072 \\
\hline & & Patient & $0.004 \pm 0.003$ & \\
\hline \multirow[t]{2}{*}{11} & Chromium $(\mathrm{Cr})$ & Healthy & $0.001 \pm 0.001$ & 0.720 \\
\hline & & Patient & $0.001 \pm 0.001$ & \\
\hline \multirow[t]{2}{*}{12} & Manganese (Mn) & Healthy & $0.002 \pm 0.001$ & 0.241 \\
\hline & & Patient & $0.001 \pm 0.0004$ & \\
\hline \multirow[t]{2}{*}{13} & Ferrum $(\mathrm{Fe})$ & Healthy & $0.03 \pm 0.04$ & 0.168 \\
\hline & & Patient & $0.003 \pm 0.004$ & \\
\hline \multirow[t]{2}{*}{14} & Nickel (Ni) & Healthy & $0.005 \pm 0.003$ & 0.150 \\
\hline & & Patient & $0.003 \pm 0.001$ & \\
\hline \multirow[t]{2}{*}{15} & Cuprum $(\mathrm{Cu})$ & Healthy & $0.003 \pm 0.0005$ & 0.447 \\
\hline & & Patient & $0.003 \pm 0.001$ & \\
\hline \multirow[t]{2}{*}{16} & Zinc $(\mathrm{Zn})$ & Healthy & $0.04 \pm 0.01$ & 0.531 \\
\hline & & Patient & $0.04 \pm 0.02$ & \\
\hline
\end{tabular}
signal to continuous signal for the healthy and patient groups as displayed in Figures $1 \mathrm{~A}$ and B, respectively.

The Mean and standard deviation of each extracted feature from the signals are outlined in Table 2 that the code " 0 " represents the patient, and the "1" represents the healthy person. The significance of each of the attributes 

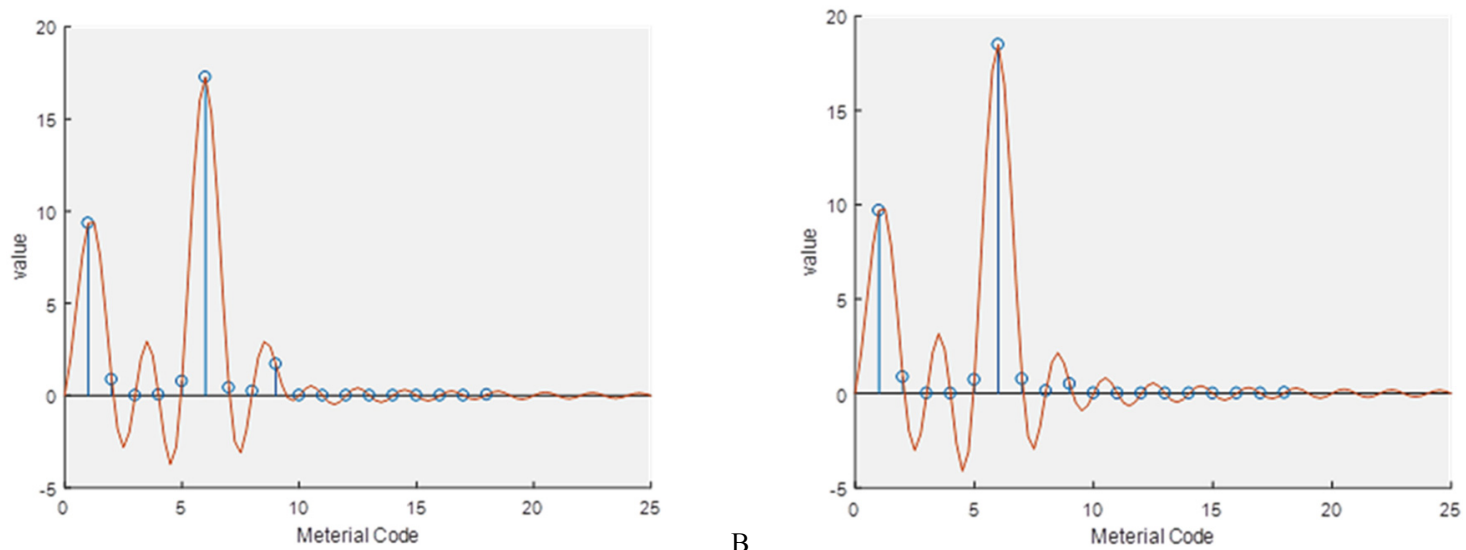

Fig. 1. The mathematical conversion of the discrete signal to continuous signal for (a) healthy and (b) patient groups. The horizontal axis indicates material codes that are according to the first column of Table 1.

Table 2. The average and standard deviation of each extracted feature. The code " 0 " represents the patient and the "1" represents the healthy person

\begin{tabular}{lccc}
\hline Feature & Code & Mean & SD \\
\hline Energy & 0 & 1470.686145 & 558.4875117 \\
& 1 & 1704.870000 & 181.9898108 \\
RMS & 0 & 3.837300 & 0.8996493 \\
& 1 & 4.103310 & 0.2181083 \\
Mean & 0 & 1.195891 & 0.2819322 \\
& 1 & 1.294310 & 0.0597468 \\
STD & 0 & 3.663836 & 0.8610910 \\
& 1 & 2.572400 & 0.0552325 \\
Skewness & 0 & 2.614436 & 0.0811879 \\
Autocorrelation & 1 & 3.912800 & 0.2196928 \\
& 0 & 76.2513 & 245.2864 \\
\hline
\end{tabular}

Table 3. The analysis of variance (ANOVA) test shows which extracted feature can help to identify healthy and patient people.

\begin{tabular}{llll}
\hline Feature & F & P value & df. \\
\hline Energy & 1.597 & 0.222 & 20 \\
RMS & 0.826 & 0.375 & 20 \\
Mean & 1.166 & 0.294 & 20 \\
STD & 15.930 & 0.001 & 20 \\
Skewness & 335.343 & 0.005 & 20 \\
Autocorrelation & 0.421 & 0.517 & 20 \\
\hline
\end{tabular}

was examined using ANOVA test, as shown in Table 3. As observable in Table 3, skewness and variance as signal features were found to be relevant in identifying healthy and cancerous groups.

\section{Discussion}

In this study, the concentration of the trace elements in the scalp hair samples was determined with EDXRF using signal processing techniques that can be used as a screening tool for prostate cancer. From our results, it can be seen that there is a significant difference in the amount Al, $\mathrm{Si}$, and $\mathrm{P}$ between patient and healthy groups. In a study, a significant difference between trace elements concentrations such as $\mathrm{Fe}$, magnesium $(\mathrm{Mg})$, zinc $(\mathrm{Zn})$, and $\mathrm{Si}$ was observed between patient and healthy groups (24). Although $\mathrm{Fe}, \mathrm{Mg}$, and $\mathrm{Zn}$ were investigated in the present study, no statistically significant difference was observed in the concentration of these trace elements in the scalp hair samples of patients and healthy groups.

To our knowledge, this is the first study that evaluated the spectrum obtained of hair samples through EDXRF as a signal and also extracted the signal features. In the current study, after converting a discrete signal continuously, the characteristics of the energy, mean, RMS, variance, skewness and autocorrelation were obtained. Skewness and variance were found to be relevant in identifying people with cancer, as shown in Table 3. In fact, skewness, as of asymmetry of a signal and variance, as the most common statistical method for time-domain feature extraction were the most successful feature.

In the present study, we used the XRF technique for hair sample analysis. There is a similar technique called X-ray diffraction (XRD) technique. Although both techniques use an X-ray source and detector, XRD determines the mineralogy. On the other hand, XRF is useful for elemental analysis, whereas XRD is for compound analysis and measure the degree of crystallinity.

Several studies have investigated the XRF technique to find a relationship between elements concentration and exiting cancers such as breast, colon, and prostate $(19,24$, 25). A previous study by Maziar et al. demonstrated that trace elements analysis of hair samples through XRF 
technique can be a novel and sensitive tool to detect breast cancer in comparison with mammography (25). In another study, Zaichick et al. using EDXRF have shown that there is a significant decrease in the prostatic tissue levels of $\mathrm{Zn}$ and rubidium $(\mathrm{Rb})$ in cancerous tissues compared with normal tissues. Furthermore, the prostatic tissue levels of bromine $(\mathrm{Br})$ and strontium $(\mathrm{Sr})$ were significantly higher in cancerous tissues than in normal tissues (16).

It has been shown that the concentrations of selenium $(\mathrm{Se}), \mathrm{Zn}$, copper $(\mathrm{Cu})$, germanium $(\mathrm{Ge})$, and boron $(\mathrm{B})$, $\mathrm{Fe}$, and $\mathrm{Mg}$ are significantly lower in patients with cancer disease. Mineral element analysis of hair using an atomic emission spectrophotometer with inductively coupled plasma (ICP-OES) and inductively coupled plasma mass spectrometry (ICP-MS) has demonstrated that abovementioned elements were significantly lower in three groups of cancer patients $(\mathrm{n}=299$, i.e., hormonedependent cancer, cancer of the alimentary tract, and cancer with high glycolytic activity) than the control group (n =100) (23).

Our study had several potential limitations. The sample size of our study is very small. To evaluate the efficacy of the XRF technique a large sample size will be required. In the present study, we defined inclusion and exclusion criteria. Of note, economic conditions, genetic, climatic conditions, etc. may have an effect on the trace elements' concentrations of hair samples. However, our study is a primary and pilot study that can help the next future studies.

\section{Conclusion}

In conclusion, our study suggests that the analysis of trace elements' concentrations of human hair samples through the XRF technique may be a non-invasive and cost-effective method to screen prostate cancer. Since many statistical tests depend on the number of sample sizes and the number of samples in this study is very low, more data should be used.

\section{Acknowledgments}

The authors would like to thank Laboratory personnel at Payambaran Hospital for their kind and helpful collaboration, personnel at Shohada-e-Tajrish Hospital, and Labbafinejad Hospital for kind collaboration and sample collection, and Dr. Emad Alddin Hosseini Toudeshki for his help in sample collection. This study was granted by the research chancellor of Iran University of Medical Sciences, Tehran, Iran.

\section{Ethical standards}

This study involved human participants, and it was conducted considering ethical responsibilities according to the World Medical Association and the Declaration of Helsinki. The study was approved by the ethics committee of Iran University of Medical Sciences, Tehran, Iran. Ethics No. is IR.IUMS.FMD.REC.1396.9413338003. Informed consent was obtained from all individual participants prior to their inclusion in the study.
Conflict of Interests

The authors declare that they have no competing interests.

\section{References}

1. Siegel RL, Miller KD, Jemal A. Cancer statistics, 2018. CA Cancer J Clin. 2018;68(1):7-30.

2. Ghaffari H, Beik J, Talebi A, Mahdavi SR, Abdollahi H. New physical approaches to treat cancer stem cells: a review. Clin Transl Oncol. 2018;20:1502-21.

3. Jemal A, Center MM, DeSantis C, Ward EM. Global patterns of cancer incidence and mortality rates and trends. Cancer Epidemiol Biomarkers Prev. 2010;19(8):1893-907

4. Hsing AW, Tsao L, Devesa SS. International trends and patterns of prostate cancer incidence and mortality. Int J Cancer. 2000;85(1):607.

5. Mallick S, Blanchet $P$, Multigner L. Prostate cancer incidence in guadeloupe, a French Caribbean archipelago. Eur Urol. 2005;47(6):769-72.

6. Askari F, Parizi M, Rashidkhani B. Dietary patterns and prostate cancer: A case-control study. Iran J Nutr Sci Food Technol. 2013;8(3):17-25.

7. Barrett A, Dobbs J, Morris S, Roques T. Practical radiotherapy planning. 4th ed. London. CRC Press. 2009.

8. Taneja SS. Imaging in the diagnosis and management of prostate cancer. Rev Urol. 2004;6(3):101-13.

9. Al-Abany M, Steineck G, Agren Cronqvist AK, Helgason AR. Improving the preservation of erectile function after external beam radiation therapy for prostate cancer. Radiother Oncol. 2000;57(2):201-6.

10. Smith DS, Humphrey PA, Catalona WJ. The early detection of prostate carcinoma with prostate specific antigen: the Washington University experience. Cancer. 1997;80(9):1852-6.

11. Thompson IM, Pauler DK, Goodman PJ, Tangen CM, Lucia MS, Parnes HL, et al. Prevalence of prostate cancer among men with a prostate-specific antigen level $<$ or $=4.0 \mathrm{ng}$ per milliliter. N Engl J Med. 2004;350:2239-46.

12. Harvey CJ, Pilcher J, Richenberg J, Patel U, Frauscher F. Applications of transrectal ultrasound in prostate cancer. Br J Radiol. 2012;85 Spec No 1:S3-17.

13. Rodrigues G, Warde P, Pickles T, Crook J, Brundage M, Souhami L, et al. Pre-treatment risk stratification of prostate cancer patients: A critical review. Can Urol Assoc J. 2012;6(2):121-7.

14. Catalona WJ, Partin AW, Finlay JA, Chan DW, Rittenhouse HG, Wolfert RL, et al. Use of percentage of free prostate-specific antigen to identify men at high risk of prostate cancer when PSA levels are 2.51 to $4 \mathrm{ng} / \mathrm{mL}$ and digital rectal examination is not suspicious for prostate cancer: an alternative model. Urology. 1999;54(2):220-4.

15. Gyorkey F, Min KW, Huff JA, Gyorkey P. Zinc and magnesium in human prostate gland: normal, hyperplastic, and neoplastic. Cancer Res. 1967;27(8):1348-53.

16. Zaichick V, Zaichick S. Trace Element Contents in Adenocarcinoma of Human Prostate Investigated by Energy Dispersive X-Ray Fluorescent Analysis. J Adenocarcinoma. 2016;1:1. 17. Kaba M, Pirincci N, Yuksel MB, Gecit I, Gunes M, Ozveren H, et al. Serum levels of trace elements in patients with prostate cancer. Asian Pac J Cancer Prev. 2014;15(6):2625-9.

18. Kolmogorov Y, Kovaleva V, Gonchar A. Analysis of trace elements in scalp hair of healthy people, hyperplasia and breast cancer patients with XRF method. Nucl Instrum Methods Phys Res, Sect A. 2000;448(1):457-60

19. Geraki K, Farquharson MJ, Bradley DA, Hugtenburg RP. A synchrotron XRF study on trace elements and potassium in breast tissue. Nucl Instrum Methods Phys Res, Sect A. 2004;213:564-8.

20. Onuwa P, Nnamonu L, Eneji I, Sha'Ato R. Analysis of Heavy Metals in Human Scalp Hair Using Energy Dispersive X-Ray Fluorescence Technique. J Anal Sci, Methods Instrum. 2012;2(4):187-93.

21. Qayyum MA, Shah MH. Comparative study of trace elements in blood, scalp hair and nails of prostate cancer patients in relation to healthy donors. Biol Trace Elem Res. 2014;162(1-3):46-57.

22. Eken A, Kaya E, Endirlik B, Erdem O, Akay C, Ozgok Y. Evaluation of trace element levels in patients with prostate cancer, 
$\mathrm{XRF}$ analysis of human hair as a prostate cancer screening

benign prostatic hyperplasia and chronic prostatitis. Gulhane Med J. 2016; $58: 1$

23. Czerny B, Krupka K, Arowski M, Seremak-Mrozikiewicz A Screening of Trace Elements in Hair of the Female Population with Different Types of Cancers in Wielkopolska Region of Poland. Sci World J. 2014;2014:15

24. Zhang R, Li L, Sultanbawa Y, Xu ZP. X-ray fluorescence imaging of metals and metalloids in biological systems. Am J Nucl Med Mol Imag. 2018;8(3):169-88.

25. Maziar A, Shahbazi-Gahrouei D, Tavakoli MB, Changizi V. Non Invasive XRF Analysis of Human Hair for Health State Determination of Breast Tissue. Iran J Cancer Prev. 2015;8(6):e3983. 